\title{
Thermal analysis of halogenated rubber cured with a new cross-linking system
}

\author{
Anna Dziemidkiewicz ${ }^{1}$ [ $\cdot$ Magdalena Maciejewska $^{1} \cdot$ Martyna Pingot $^{1}$
}

Received: 15 October 2018 / Accepted: 1 October 2019 / Published online: 2 November 2019

(c) The Author(s) 2019

\begin{abstract}
The aim of this work was to examine the influence of new curing agents proposed for brominated butyl rubber (BIIR) on the cross-linking process of rubber compounds and the thermal behavior of the vulcanizates. Rubber blends that were filled with carbon black and contained acetylacetonates of different transition metals in the presence of triethanolamine (TEOA) as new cross-linking agents were prepared. The performed studies showed that metal acetylacetonates $(\mathrm{Me}(\mathrm{acac}))$ are effective cross-linking agents for BIIR, which was confirmed by high values of the torque increment $(\Delta M)$ and significant cross-linking degree of the vulcanizates $\left(\alpha_{(\mathrm{T})}\right)$. The most active curing agent seems to be iron acetylacetonate $(\mathrm{Fe}(\mathrm{acac}))$. Its application results in a shorter optimal vulcanization time, lower onset vulcanization temperature and similar vulcanization enthalpy compared to the BIIR cured with a sulfur curing system. The BIIR vulcanizates cured with $\mathrm{Me}(\mathrm{acac})$ reveal good mechanical properties with tensile strengths in the range of 9-14 MPa and better damping properties comparing to the sulfur-cured rubber. The proposed curing agents do not significantly affect the thermal stability of the BIIR vulcanizates.
\end{abstract}

Keywords Thermal analysis $\cdot$ DSC $\cdot$ TG $\cdot$ DMA $\cdot$ Halogenated butyl rubber $\cdot$ Curing agents

\section{Introduction}

Currently, elastomers with special properties, such as the resistance to considerably lowered or elevated temperatures, frequently in the medium of various technical fluids, play an increasingly greater role in materials engineering. The thermal stability, which determines their functional usability, is defined as a range of temperatures, within which elastomers retain their specific properties. The lower limit of the elastomer elastic state is determined by the glass-transition or crystallization temperature, while the upper limit is determined by the temperature of degradation, depolymerization or destruction. The thermal stability is closely connected with the macromolecule structure that determines both

Anna Dziemidkiewicz

anna.dziemidkiewicz@edu.p.lodz.pl

Magdalena Maciejewska

magdalena.maciejewska@p.lodz.pl

Martyna Pingot

martyna.pingot@gmail.com

1 Institute of Polymer and Dye Technology, Lodz University of Technology, Stefanowskiego 12/16, 90-924 Lodz, Poland reversible and irreversible transitions under the influence of temperature [1].

Thermal analysis can be broadly defined as the analytical techniques that study the behavior of materials as a function of temperature [2]. These techniques provide very useful tools for the characterization and identification of both elastomer compounds and finished rubber products. Thermal analysis allows for the compositional studies, characterization of the thermal and oxidative stability, glass-transition temperature $\left(T_{\mathrm{g}}\right)$, dynamic mechanical properties and thermal evaluation of the vulcanization process of the elastomeric systems [3]. The most frequently used methods of thermal analysis in elastomers are differential scanning calorimetry (DSC), thermogravimetry (TG) and dynamic mechanical analysis (DMA).

TG measures the mass changes in a material as it is heated, cooled, or held at a constant temperature in an inert atmosphere. It is commonly used to determine the composition and the thermal stability of elastomeric composites at temperatures up to $1000{ }^{\circ} \mathrm{C}$.

DSC measures the amount of energy absorbed or released by a sample as it is heated, cooled, or held isothermally at a constant temperature. DSC measures the heat flow associated with the phase transitions in materials as a function of 
time and temperature. Such measurements provide quantitative and qualitative information about the physical or chemical changes that involve exothermic or endothermic processes or the changes in heat capacity [2].

Finally, DMA evaluates the relaxation transitions and the viscoelastic properties of materials over a range of temperatures [3]. The main parameters measured with DMA for elastomers are the storage and loss moduli and their ratio, $\tan \delta$, called the mechanical loss factor.

Butyl rubber (IIR) is among the most widely used commercially available synthetic elastomers today. IIR is the copolymer of isobutylene (98-99\%) and a small amount of isoprene (1-2\%) added to enable vulcanization [4-6]. It is the first of the limited functionality polymers, which combines the capability of cross-linking with a sulfur system of unsaturated rubber with the excellent chemical resistance of a saturated polymer [5]. IIR was patented in 1937 and first commercialized in 1943 [5, 6]. The primary attributes of butyl rubber are excellent impermeability for use as an air barrier and good flex fatigue properties, which result from low levels of unsaturation $[4,6]$.

The development of halogenated butyl rubbers (XIIR) started in the 1950s [6]. As a result of halogenation, the bound isoprene units are converted to the corresponding halo-substituted forms of the isoprene units [7]. These polymers greatly extended the usefulness of IIR by having faster curing rates $[5,8]$ and an increased polarity without affecting the desirable impermeability and fatigue properties. The increased polarity enabled covulcanization with the generalpurpose elastomers that are used in tire compounds.

Today, tire inner liners are the largest application for halogenated butyl rubber. Both chlorobutyl (CIIR) and bromobutyl (BIIR) rubbers are used commercially. In addition to tire applications, other properties of butyl rubbers, such as the resistance to ultraviolet light degradation, oxidation, and ozone, viscoelastic (dampening) characteristics and thermal stability, make these polymers as the material of choice for pharmaceutical stoppers, construction sealants, hoses, vibration isolation and mechanical goods $[5,6]$.

Vulcanization, cross-linking or curing, is one of the most important processes in rubber technologies $[9,10]$. Uncured elastomers flow under an applied stress, which limits their application as an engineering material [5]. Vulcanization is the process of transforming a plastic rubber compound into a highly elastic product by forming a three-dimensional crosslinked network structure in the rubber matrix. It allows for the conversion of the raw material into final rubber products, the engineering material with desired physical, chemical and mechanical properties. [11].

In IIR, the hydrogen atoms positioned $\alpha$ to the carbon-carbon double bond enable the vulcanization into a cross-linked network with sulfur and organic accelerators. However, the low degree of unsaturation requires the application of ultra-accelerators, such as thiuram, thiocarbamate or peroxide curing [12]. Phenolic resins, bias-zidoformates and quinone derivatives can also be used as curing agents of this rubber [6]. Moreover, halogenated butyl rubbers may be cured by $\mathrm{ZnO}$ alone, a characteristic imparted by the reactivity of an allylic halide. Although the $\mathrm{C}-\mathrm{C}$ cross-links generated by this reaction are thermally stable, the vulcanizates exhibit poor wear resistance and dynamic properties [5]. However, all of the known methods of elastomer vulcanization have some disadvantages, such as the application of carcinogenic or harmful products or not sufficiently good properties of the obtained vulcanizates [13]. Therefore, scientists are still looking for new methods of vulcanization.

The Heck-type reactions, for the carbon-carbon $(\mathrm{C}=\mathrm{C})$ bond formation between aryl/vinyl halides and olefins, are very important in organic chemistry. They provide the simplest and most efficient way to synthesize various compounds useful in the pharmaceutical and agrochemical industries [14-16]. Typically, Heck reactions are catalyzed by expensive palladium catalysts and proceed in the presence of a base, which is responsible for binding $\mathrm{HBr}$, which is produced during the reaction [16]. Palladium is usually the preferred transition metal as Pd catalysts exhibit excellent performance [17]. However, due to high price of Pd catalysts, there is a growing interest in using less expensive transition metal. Wang and Yang discussed catalytic systems containing Ni-, Co-, $\mathrm{Cu}$ - or Fe-based catalysts, which were found to be active for Heck-type reaction as well [18].

Despite being used in many applications, the Heck-type reactions have not been applied to the rubber industry so far. Preliminary research conducted in the Institute of Polymer and Dye Technology (Lodz University of Technology, Poland) [19] confirmed that selected $\mathrm{Me}$ (acac) in the presence of TEOA are active curing agents for chloroprene rubber, which probably act via Heck-type reaction.

In our studies, we examined the activity of cheap Fe, Mn, $\mathrm{Ni}$ or $\mathrm{Cu}$ acetylacetonates as curing agents for BIIR based on the Heck-type reaction. These metal complexes were applied instead of expensive Pd or Pt catalysts, commonly used in such reactions [18]. To ensure the alkaline environment of the reaction, TEOA was applied. Additionally, TEOA was responsible for the regeneration of the catalyst through the bonding of $\mathrm{HBr}$, which was produced during the cross-linking reaction. The halogenation and unsaturation of the bonds, which are necessary in this reaction, were ensured by using BIIR. The greatest advantage of using $\mathrm{Me}(\mathrm{acac})$ is that a high activity can be achieved with a very small amount of curing agents. This makes $\mathrm{Me}(\mathrm{acac})$ not only valuable from an economical point of view but also important for human health and the environment. Moreover, it should be noted that the presented curing system is an entirely new approach for BIIR and has not been described 
in the literature so far. Therefore, it was important to study their effect on the vulcanization process and the thermal behavior of BIIR composites.

\section{Experimental}

\section{Materials}

BIIR (BIIR-2302) with $1.9 \pm 0.2 \%$ of bromination and Mooney's viscosity $\operatorname{ML}(1+8) 125^{\circ} \mathrm{C}: 32 \pm 5$ was used as the polymer matrix. BIIR was provided by Torimex-Chemicals (Konstantynów Łódzki, Poland). Me(acac), such as iron(III) (Fe(acac)), manganese(II) (Mn(acac)), nickel(II) ( $\mathrm{Ni}(\mathrm{acac}))$ and copper(II) $(\mathrm{Cu}(\mathrm{acac}))$ acetylacetonates, were used as curing agents. All acetylacetonates were purchased from Sigma-Aldrich (Poznan, Poland). Carbon black (CB) (N-550) supplied from Konimpex (Konin, Poland) was used as a filler. To ensure the alkaline environment of the cross-linking process, TEOA provided by Chempur (Piekary Śląskie, Poland) was used. Sulfur, $\mathrm{ZnO}, \mathrm{MgO}$, 2-mercaptobenzothiazole disulfide (MBTS) and tetramethylthiuram disulfide (TMTD) used to prepare the ref. sample were purchased from Sigma-Aldrich (Poznan, Poland). All chemicals were used as received without further purification.

\section{Preparation and characterization of rubber compounds}

The mixing procedure was carried out using an internal mixer (Brabender N50, Brabender GmbH \& Co. KG, Duisburg, Germany) maintained at $50{ }^{\circ} \mathrm{C}$ and a rotor speed of $50 \mathrm{rpm}$. Rubber compounding was performed with a twostage mixing technique. In the first mixing stage, the filler and TEOA were incorporated into raw BIIR after 4 min of plasticizing. In the second stage, the $\mathrm{Me}(\mathrm{acac})$ were added and allowed to achieve good dispersion and distribution of all the ingredients. Table 1 illustrates the formulations of the BIIR compounds used in this work. All the compositions are presented as parts per hundred of rubber (phr). As the ref. sample, a rubber compound containing the traditionally used vulcanization system based on sulfur, $\mathrm{ZnO}, \mathrm{MgO}$, MBTS and TMTD was prepared and studied.

The BIIR composites were vulcanized at the optimal vulcanization time (TC95) measured during the rheometrical tests with a D-RPA 3000 rheometer (MonTech, Buchen, Germany). The vulcanization was carried out at $160{ }^{\circ} \mathrm{C}$ using a hydraulic press with electrical heating. The plates obtained had a thickness of approximately $1 \mathrm{~mm}$.

The degree of vulcanizate cross-linking $\left(\alpha_{\mathrm{T}}\right)$ was calculated based on solvent-swelling measurements in toluene, according to standard PN-ISO 817:2001/ap1:2002.
Table 1 General composition of the BIIR-based rubber compounds, phr

\begin{tabular}{|c|c|c|c|c|}
\hline Compound & BIIR & $\mathrm{CB}$ & TEOA & $\mathrm{Me}(\mathrm{acac})$ \\
\hline Ref. sample & 100 & 30 & + sulfur system $^{\mathrm{a}}$ & \\
\hline $0.2 \mathrm{Fe} / 1 \mathrm{TEOA}$ & 100 & 30 & 1 & $0.2 \mathrm{Fe}(\mathrm{acac})$ \\
\hline $0.2 \mathrm{Mn} / 1 \mathrm{TEOA}$ & 100 & 30 & 1 & $0.2 \mathrm{Mn}(\mathrm{acac})$ \\
\hline $0.2 \mathrm{Ni} / 1 \mathrm{TEOA}$ & 100 & 30 & 1 & $0.2 \mathrm{Ni}(\mathrm{acac})$ \\
\hline $0.2 \mathrm{Cu} / 1 \mathrm{TEOA}$ & 100 & 30 & 1 & $0.2 \mathrm{Cu}(\mathrm{acac})$ \\
\hline $0.3 \mathrm{Fe} / 1 \mathrm{TEOA}$ & 100 & 30 & 1 & $0.3 \mathrm{Fe}(\mathrm{acac})$ \\
\hline $0.3 \mathrm{Mn} / 1 \mathrm{TEOA}$ & 100 & 30 & 1 & $0.3 \mathrm{Mn}(\mathrm{acac})$ \\
\hline $0.3 \mathrm{Ni} / 1 \mathrm{TEOA}$ & 100 & 30 & 1 & $0.3 \mathrm{Ni}(\mathrm{acac})$ \\
\hline $0.3 \mathrm{Cu} / 1 \mathrm{TEOA}$ & 100 & 30 & 1 & $0.3 \mathrm{Cu}(\mathrm{acac})$ \\
\hline $0.2 \mathrm{Fe} / 3 \mathrm{TEOA}$ & 100 & 30 & 3 & $0.2 \mathrm{Fe}(\mathrm{acac})$ \\
\hline $0.2 \mathrm{Mn} / 3 \mathrm{TEOA}$ & 100 & 30 & 3 & $0.2 \mathrm{Mn}(\mathrm{acac})$ \\
\hline $0.2 \mathrm{Ni} / 3$ TEOA & 100 & 30 & 3 & $0.2 \mathrm{Ni}(\mathrm{acac})$ \\
\hline $0.2 \mathrm{Cu} / 3 \mathrm{TEOA}$ & 100 & 30 & 3 & $0.2 \mathrm{Cu}(\mathrm{acac})$ \\
\hline $0.3 \mathrm{Fe} / 3 \mathrm{TEOA}$ & 100 & 30 & 3 & $0.3 \mathrm{Fe}(\mathrm{acac})$ \\
\hline $0.3 \mathrm{Mn} / 3$ TEOA & 100 & 30 & 3 & $0.3 \mathrm{Mn}(\mathrm{acac})$ \\
\hline $0.3 \mathrm{Ni} / 3$ TEOA & 100 & 30 & 3 & $0.3 \mathrm{Ni}(\mathrm{acac})$ \\
\hline $0.3 \mathrm{Cu} / 3 \mathrm{TEOA}$ & 100 & 30 & 3 & $0.3 \mathrm{Cu}(\mathrm{acac})$ \\
\hline $0.2 \mathrm{Fe} / 4 \mathrm{TEOA}$ & 100 & 30 & 4 & $0.2 \mathrm{Fe}(\mathrm{acac})$ \\
\hline $0.2 \mathrm{Mn} / 4 \mathrm{TEOA}$ & 100 & 30 & 4 & $0.2 \mathrm{Mn}(\mathrm{acac})$ \\
\hline $0.2 \mathrm{Ni} / 4 \mathrm{TEOA}$ & 100 & 30 & 4 & $0.2 \mathrm{Ni}(\mathrm{acac})$ \\
\hline $0.2 \mathrm{Cu} / 4 \mathrm{TEOA}$ & 100 & 30 & 4 & $0.2 \mathrm{Cu}(\mathrm{acac})$ \\
\hline
\end{tabular}

${ }^{\mathrm{a}} \mathrm{ZnO}-5 ; \mathrm{S}-0.5 ; \mathrm{MBTS}-1.5 ; \mathrm{TMTD}-0.25 ; \mathrm{MgO}-0.5$ [6]

The tensile tests were carried out according to the standard PN-ISO 37:1998, using a Zwick 1435 universal testing machine (Zwick GmbH, Ulm, Germany). The samples had a standard dumbbell shape.

The resistance of the BIIR vulcanizates to thermo-oxidative aging was studied in accordance with the standard PN-88/C-04207. The vulcanizates were subjected to circulating air at a temperature of $70{ }^{\circ} \mathrm{C}$ for $168 \mathrm{~h}$. The tensile properties, such as the tensile strength (TS) and the elongation at break (EB), were measured before and after the aging procedure. The aging coefficient $\left(A_{\mathrm{f}}\right)$ was calculated from the following relationship:

$A_{\mathrm{f}}=(\mathrm{TS} \cdot \mathrm{EB})_{\text {after aging }} /(\mathrm{TS} \cdot \mathrm{EB})_{\text {before aging }}$

where $A_{\mathrm{f}}$-aging coefficient, TS—tensile strength (MPa), EB-elongation at break (\%).

Thermal evaluation of the vulcanization process was performed using a DSC1 analyzer (Mettler Toledo, Greifensee, Switzerland). The samples were heated from -100 to $250{ }^{\circ} \mathrm{C}$ at a heating rate of $10{ }^{\circ} \mathrm{C} \mathrm{min}^{-1}$.

The thermal stability of the vulcanizates was studied using a TGA/DSC1 (Mettler Toledo, Greifensee, Switzerland) analyzer. The samples were heated from 25 to $600{ }^{\circ} \mathrm{C}$ in an argon atmosphere $\left(60 \mathrm{~mL} \mathrm{~min}{ }^{-1}\right)$ at a heating rate of $10{ }^{\circ} \mathrm{C} \mathrm{min}^{-1}$. Next, the gas was changed to air 
$\left(60 \mathrm{~mL} \mathrm{~min}^{-1}\right)$, and the heating was continued up to $900{ }^{\circ} \mathrm{C}$ at the same heating rate.

The dynamic mechanical measurements were taken using a tension mode with a DMA/SDTA861e analyzer (Mettler Toledo, Greifensee, Switzerland). The measurements of the dynamic moduli were performed over the temperature range of -80 to $100{ }^{\circ} \mathrm{C}$ with a heating rate of $3{ }^{\circ} \mathrm{C} \mathrm{min}^{-1}$, a frequency of $1 \mathrm{~Hz}$, and a strain amplitude of $0.05 \%$.

\section{Results and discussion}

\section{Cure characteristics of BIIR and the cross-linking density of vulcanizates}

The effect of the Me(acac) on the cross-linking process of the BIIR composites was investigated based on the rheological measurements (Table 2). The cure characteristics of the rubber compound can be monitored by following the increase in its viscosity (known as modulus) over a time at a specified temperature. The increase in modulus during vulcanization (torque increment) could be used as an indirect

Table 2 Cure characteristics of BIIR compounds and the degree of cross-linking calculated on the basis of the solvent swelling measurements in toluene

\begin{tabular}{llllll}
\hline Compound & $M_{\mathrm{L}} / \mathrm{dNm}$ & $\Delta M / \mathrm{dNm}$ & $T S 2 / \mathrm{min}$ & $T C 95 / \mathrm{min}$ & $\alpha_{(\mathrm{T})} /-$ \\
\hline Ref. sample & 1.6 & 5.3 & 0.8 & 19 & 0.48 \\
$0.2 \mathrm{Fe} / 1$ TEOA & 1.7 & 3.7 & 1.1 & 29 & 0.42 \\
$0.2 \mathrm{Mn} / 1$ TEOA & 1.7 & 2.5 & 0.8 & 25 & 0.30 \\
$0.2 \mathrm{Ni} / 1$ TEOA & 1.9 & 1.4 & 1.0 & 36 & 0.23 \\
$0.2 \mathrm{Cu} / 1$ TEOA & 1.7 & 0.7 & 0.7 & 28 & 0.14 \\
$0.3 \mathrm{Fe} / 1$ TEOA & 1.7 & 4.9 & 0.8 & 30 & 0.48 \\
$0.3 \mathrm{Mn} / 1$ TEOA & 1.7 & 2.6 & 0.7 & 23 & 0.34 \\
$0.3 \mathrm{Ni} / 1$ TEOA & 1.7 & 2.4 & 0.8 & 25 & 0.29 \\
$0.3 \mathrm{Cu} / 1$ TEOA & 1.8 & 0.9 & 0.5 & 13 & 0.16 \\
$0.2 \mathrm{Fe} / 3$ TEOA & 1.7 & 4.8 & 0.8 & 14 & 0.51 \\
$0.2 \mathrm{Mn} / 3$ TEOA & 1.6 & 3.2 & 0.7 & 38 & 0.43 \\
$0.2 \mathrm{Ni} / 3$ TEOA & 1.7 & 3.4 & 0.7 & 34 & 0.45 \\
$0.2 \mathrm{Cu} / 3$ TEOA & 1.8 & 1.2 & 0.5 & 13 & 0.18 \\
$0.3 \mathrm{Fe} / 3$ TEOA & 1.7 & 5.5 & 0.6 & 13 & 0.58 \\
$0.3 \mathrm{Mn} / 3$ TEOA & 1.7 & 3.1 & 0.6 & 36 & 0.45 \\
$0.3 \mathrm{Ni} / 3$ TEOA & 1.7 & 3.3 & 0.6 & 34 & 0.48 \\
$0.3 \mathrm{Cu} / 3$ TEOA & 1.9 & 0.9 & 0.6 & 11 & 0.16 \\
$0.2 \mathrm{Fe} / 4$ TEOA & 1.6 & 4.7 & 0.7 & 11 & 0.54 \\
$0.2 \mathrm{Mn} / 4$ TEOA & 1.7 & 2.9 & 0.6 & 40 & 0.40 \\
$0.2 \mathrm{Ni} / 4$ TEOA & 1.7 & 3.2 & 0.6 & 32 & 0.46 \\
$0.2 \mathrm{Cu} / 4$ TEOA & 1.8 & 1.1 & 0.6 & 11 & 0.18 \\
\hline
\end{tabular}

$M_{\mathrm{L}}$-minimum torque, $\Delta M$-torque increment during vulcanization, TS2 - scorch time, TC95-optimal vulcanization time, $\alpha_{(\mathrm{T})}$-degree of cross-linking indication of the cross-linking degree of the vulcanizates $[4,20]$.

According to the data presented in Table 2, it can be concluded that the viscosity of the uncured BIIR compounds does not depend significantly on the type of the used curing system. The BIIR cross-linked with the sulfur curing system exhibited values of $M_{\mathrm{L}}$ similar to the rubber compounds containing different $\mathrm{Me}$ (acac) and TEOA. No influence of the type and the content of the $\mathrm{Me}$ (acac) as well as the content of TEOA on $M_{\mathrm{L}}$ was achieved. This indicates a low influence of the proposed curing agents on the further processing of the rubber compounds.

Considering the $\Delta M$ during the vulcanization of the BIIR compounds, a standard sulfur system allowed for the achievement of higher $\Delta M$ values than most of the $\mathrm{Me}$ (acac). Only the rubber compounds containing $\mathrm{Fe}$ (acac) exhibit a $\Delta M$ similar to or slightly lower than that of the ref. sample (except for the $0.2 \mathrm{Fe} / 1 \mathrm{TEOA}$ system). This confirmed the highest activity of $\mathrm{Fe}$ (acac) in the vulcanization of BIIR. Mn(acac) and $\mathrm{Ni}(\mathrm{acac})$ seem to be less active metal complexes, which resulted in lower $\Delta M$ during the BIIR vulcanization. $\mathrm{Cu}(\mathrm{acac})$ shows the lowest activity, giving rubber compounds with $\Delta M$ values in the range of $0.7-1.2 \mathrm{dNm}$. Such low $\Delta M$ during vulcanization indicates very low effectiveness of this process. The content of the metal complex does not significantly affect the $\Delta M$ during the BIIR vulcanization, whereas with increasing amount of TEOA over 1 phr, a slightly higher activity of the curing system is observed. Therefore, it could be concluded that the type of the transition metal in the acetylacetonate and a proper amount of TEOA is crucial regarding the effectiveness of vulcanization.

Applying the proposed curing agents does not affect notably the scorch time (TS2) of BIIR in comparison with the sulfur curing system. It is very important for the safety of rubber compound processing. The optimal vulcanization times of the rubber compounds with $\mathrm{Me}$ (acac) range from 11 to $40 \mathrm{~min}$. The content of TEOA seems to influence the optimal vulcanization time, especially of the rubber compounds with $\mathrm{Fe}(\mathrm{acac})$, for which increasing the TEOA content resulted in a decrease in vulcanization time. The effect of the metal complex on TC95 is also noticeable. Due to the very low $\Delta M$ during vulcanization, compounds cured with $\mathrm{Cu}(\mathrm{acac})$ are not taken into consideration. The BIIR with $\mathrm{Fe}(\mathrm{acac})$ and 3-4 phr of TEOA exhibits the shortest vulcanization times in comparison with the ref. sample and another $\mathrm{Me}$ (acac). For this content of TEOA, rubber compounds with $\mathrm{Mn}(\mathrm{acac})$ or $\mathrm{Ni}$ (acac) were characterized with TC95 in the range of 32-40 min. The highest activity, so the shortest vulcanization time, for those catalysts can be observed for compounds containing $0.3 \mathrm{phr}$ of $\mathrm{Mn}$ (acac) or Ni(acac) and $1 \mathrm{phr}$ of TEOA. Shorter vulcanization time is beneficial from an industrial point of view, since shorter 
vulcanization time is strongly connected with lower costs of the vulcanization process.

The data in Table 2 show that the $\alpha_{\mathrm{T}}$ of the obtained vulcanizates depends on the type and the amount of the used acetylacetonate as well as the amount of TEOA. The vulcanizates containing 3 or $4 \mathrm{phr}$ of TEOA showed a higher $\alpha_{(\mathrm{T})}$ than the samples with $1 \mathrm{phr}$ of TEOA. One phr of TEOA is probably not enough to bind all $\mathrm{HBr}$ produced during the cross-linking reactions. Taking into consideration $\alpha_{(\mathrm{T})}$ of the vulcanizates cured with metal complexes, $\mathrm{Fe}$ (acac) was the most active one. This finding confirmed the results of the rheometrical measurements. Moreover, the application of $\mathrm{Fe}(\mathrm{acac})$ in the presence of 3 or $4 \mathrm{phr}$ of TEOA achieved a higher $\alpha_{(\mathrm{T})}$ than the sulfur-cross-linked BIIR. The lowest values of $\alpha_{\mathrm{T}}$ for the vulcanizates with $\mathrm{Cu}(\mathrm{acac})$ confirmed the lowest activity of this complex in the BIIR cross-linking.

\section{Thermal evaluation of BIIR vulcanization process and thermal stability of vulcanizates}

The influence of the proposed new curing system on the vulcanization process of BIIR was also studied using the DSC analysis, which allowed for the determination of the temperature and the enthalpy of vulcanization. This method is commonly used to investigate the curing process of polymers [21-24]. The results are given in Table 3. The DSC curves for the vulcanization of BIIR containing the most active metal complex $\mathrm{Fe}(\mathrm{acac})$ were presented as an example in Fig. 1.

For new cross-linking agents of BIIR, which have not been described in the literature so far, the kinetics of vulcanization is a key issue to study. Comparing the vulcanization enthalpy of the prepared rubber compounds, a high influence of the type and the amount of the used metal complex and the amount of TEOA was observed. The sulfur vulcanization of BIIR proceeds in the temperature range of $155-213{ }^{\circ} \mathrm{C}$ with an enthalpy of $13.6 \mathrm{~J} \mathrm{~g}^{-1}$. All rubber compounds cured with new curing agents showed a lower enthalpy of vulcanization. However, it is worth noticing that the compound containing the $0.2 \mathrm{Fe} / 4 \mathrm{TEOA}$ curing system was characterized with a vulcanization enthalpy similar to that of the sulfur-cured ref. sample $\left(11.0 \mathrm{~J} \mathrm{~g}^{-1}\right)$. Moreover, only the BIIR with $0.2 \mathrm{phr}$ of $\mathrm{Fe}$ (acac) and $1 \mathrm{phr}$ of TEOA exhibited higher onset vulcanization temperature compared to the reference rubber compound. It is important for technological reasons. The application of $\mathrm{Fe}$ (acac) should allow for the curing of BIIR at a lower temperature than the generally used $160{ }^{\circ} \mathrm{C}$. It should be mentioned that the rubber compounds with $\mathrm{Fe}(\mathrm{acac})$ in the presence of 3-4 phr of TEOA exhibited shorter vulcanization times as well. This generates real economic benefits for the industrial usage of the proposed curing system.
Table 3 Thermal evaluation of the vulcanization process and the thermal stability of BIIR composites

\begin{tabular}{lclll}
\hline Compound & $\begin{array}{c}\text { Vulcanization } \\
\text { enthalpy } / \mathrm{J} \mathrm{g}^{-1}\end{array}$ & $\begin{array}{l}\text { Vulcanization } \\
\text { temperature } /{ }^{\circ} \mathrm{C}\end{array}$ & $T_{5 \%} /{ }^{\circ} \mathrm{C}$ & $T_{50 \%} /{ }^{\circ} \mathrm{C}$ \\
\hline Ref. sample & 13.6 & $155-213$ & 333 & 421 \\
$0.2 \mathrm{Fe} / 1$ TEOA & 1.8 & $178-212$ & 338 & 415 \\
$0.2 \mathrm{Mn} / 1$ TEOA & 2.3 & $171-220$ & 335 & 411 \\
$0.2 \mathrm{Ni} / 1$ TEOA & 2.0 & $174-223$ & 340 & 410 \\
$0.2 \mathrm{Cu} / 1$ TEOA & 1.3 & $179-207$ & - & - \\
$0.3 \mathrm{Fe} / 1$ TEOA & 4.8 & $150-211$ & 339 & 416 \\
$0.3 \mathrm{Mn} / 1$ TEOA & 4.5 & $163-221$ & 341 & 413 \\
$0.3 \mathrm{Ni} / 1$ TEOA & 5.1 & $154-223$ & 348 & 415 \\
$0.3 \mathrm{Cu} / 1$ TEOA & 3.6 & $163-214$ & - & - \\
$0.2 \mathrm{Fe} / 3$ TEOA & 4.4 & $146-203$ & 321 & 412 \\
$0.2 \mathrm{Mn} / 3$ TEOA & 4.1 & $147-224$ & 321 & 413 \\
$0.2 \mathrm{Ni} / 3$ TEOA & 4.2 & $159-224$ & 322 & 414 \\
$0.2 \mathrm{Cu} / 3$ TEOA & 3.9 & $157-227$ & - & - \\
$0.3 \mathrm{Fe} / 3$ TEOA & 5.6 & $140-209$ & 319 & 413 \\
$0.3 \mathrm{Mn} / 3$ TEOA & 4.5 & $157-231$ & 324 & 413 \\
$0.3 \mathrm{Ni} / 3$ TEOA & 3.6 & $166-228$ & 321 & 415 \\
$0.3 \mathrm{Cu} / 3$ TEOA & 3.8 & $177-235$ & - & - \\
$0.2 \mathrm{Fe} / 4$ TEOA & 11.0 & $145-209$ & 316 & 412 \\
$0.2 \mathrm{Mn} / 4$ TEOA & 5.4 & $152-227$ & 319 & 413 \\
$0.2 \mathrm{Ni} / 4$ TEOA & 3.6 & $163-223$ & 317 & 415 \\
$0.2 \mathrm{Cu} / 4$ TEOA & 3.4 & $149-230$ & - & - \\
\hline
\end{tabular}

$T_{5 \%}, T_{50 \%}$-temperature of $5 \%$ or $50 \%$ mass loss of the vulcanizate, respectively

Interesting results were obtained for the rubber compounds with $0.2 \mathrm{phr}$ of metal complex and $1 \mathrm{phr}$ of TEOA. The onset of vulcanization was shifted to $20-30{ }^{\circ} \mathrm{C}$ higher temperatures for all acetylacetonates. This may be due to the insufficient amount of both the complex and TEOA, which resulted in a much lower activity of these curing systems, and therefore, a very low enthalpy of vulcanization for those rubber compounds. Moreover, these results correlate with the low $\Delta M$ during vulcanization performed at $160{ }^{\circ} \mathrm{C}$ and the low $\alpha_{(\mathrm{T})}$ of the vulcanizates obtained at this temperature, which is a typical temperature of vulcanization in the rubber industry. It may be that performing rheometric measurements for these rubber compounds at a higher temperature, e.g., $180{ }^{\circ} \mathrm{C}$, would result in a higher $\Delta M$ and a higher $\alpha_{(\mathrm{T})}$.

Rubber products often work at elevated temperatures. For this reason, the TG analysis was performed to determine the effect of the proposed curing systems on the thermal stability of the BIIR vulcanizates. Measurements were not performed for the vulcanizates with $\mathrm{Cu}(\mathrm{acac})$, which showed the lowest $\alpha_{(\mathrm{T})}$ and consequently poor mechanical properties. The results are presented in Table 3. The TG/DTG curves of the BIIR vulcanizates containing the most active metal complex $\mathrm{Fe}(\mathrm{acac})$ were presented as an example in Fig. 2. 


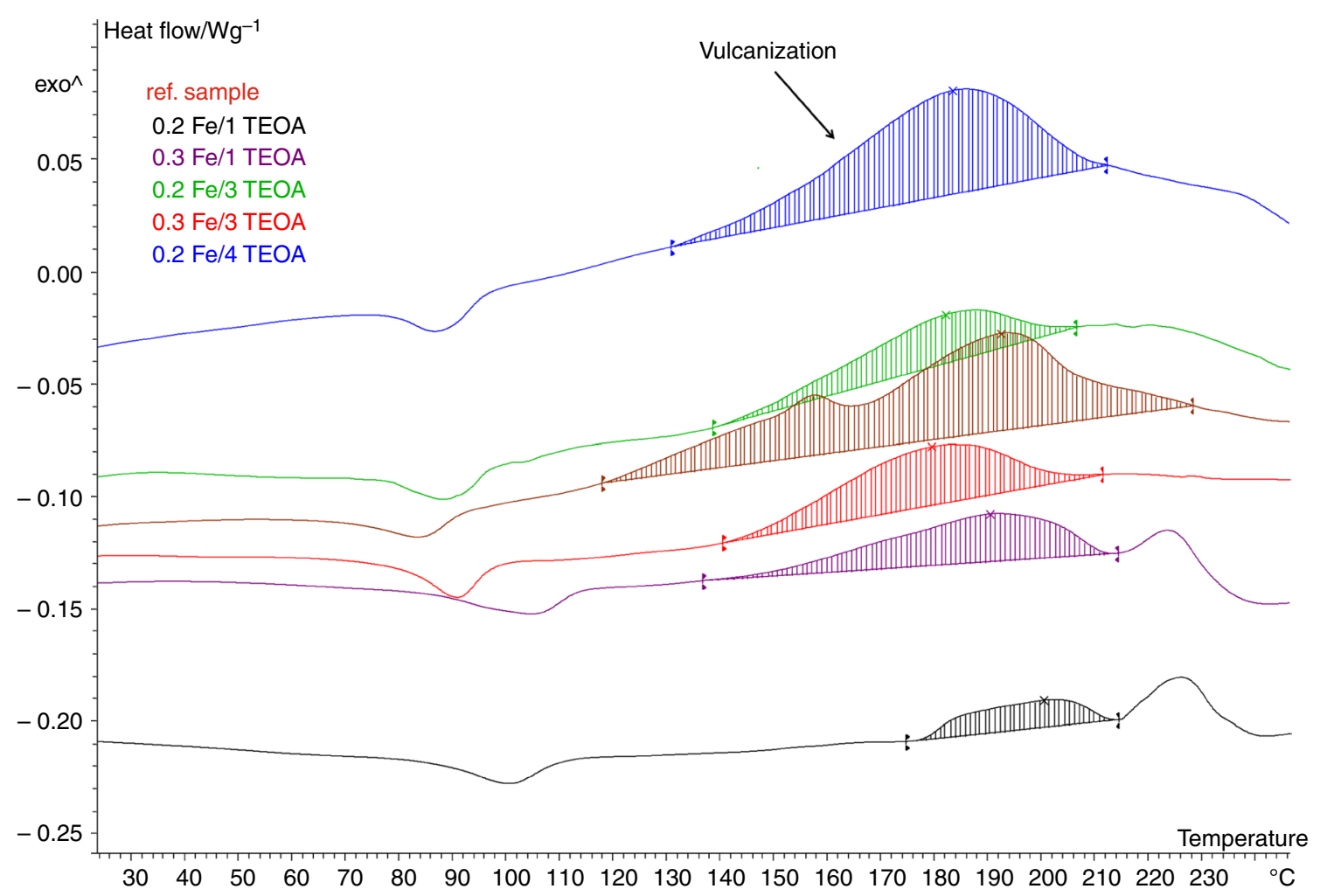

Fig. 1 DSC curves for the vulcanization of BIIR with the Fe(acac)/TEOA curing system

The TG measurements were carried out in two steps. First, the samples were heated from 25 to $600{ }^{\circ} \mathrm{C}$ in an argon atmosphere and the pyrolysis of the elastomer together with the thermal decomposition of organic compounds, such as vulcanization accelerators (for the ref. sample) or new curing agents, was observed. Above $600{ }^{\circ} \mathrm{C}$, the atmosphere of the measurement was changed to air and the mass loss corresponding to the burning of $\mathrm{CB}$ and residues from the elastomer pyrolysis was achieved. To compare the thermal stability of the vulcanizate cured with sulfur and vulcanizates containing $\mathrm{Me}(\mathrm{acac}) / \mathrm{TEOA}$ curing systems, the temperatures for $5 \%$ and $50 \%$ mass loss were determined $\left(T_{5 \%}\right.$ and $T_{50 \%}$, respectively). $T_{5 \%}$ was taken as the onset temperature of the thermal decomposition.

Regarding the $T_{5 \%}$ temperatures, a great influence of TEOA on the thermal stability of vulcanizates could be observed. The vulcanizates with 1 phr TEOA exhibited approximately $2-15{ }^{\circ} \mathrm{C}$ higher $T_{5 \%}$ compared to the ref. sample cured with sulfur. On the other hand, the vulcanizates with 3 or 4 phr TEOA showed a worse thermal stability with $T_{5 \%}$ approximately $9-17{ }^{\circ} \mathrm{C}$ lower than that for the ref. sample. The vulcanizates containing $\mathrm{Fe}(\mathrm{acac})$ exhibited slightly lower $T_{5 \%}$ compared to the other Me(acac). It could be supposed that the reduction in $T_{5 \%}$ temperature for the vulcanizates with 3 or $4 \mathrm{phr}$ TEOA could result from the low thermal stability of TEOA, which starts decomposing at the temperature above $150{ }^{\circ} \mathrm{C}$ with the removal of $\mathrm{CH}_{2} \mathrm{OH}$ groups [25]. The $T_{50 \%}$ temperatures of the vulcanizates with the proposed curing systems were only slightly lower (approximately $5-11{ }^{\circ} \mathrm{C}$ ) than those of the ref. sample. The BIIR cured with $\mathrm{Me}(\mathrm{acac}) / \mathrm{TEOA}$ curing systems was thermally stable to a temperature of approximately $320^{\circ} \mathrm{C}$, what should not considerably affect their potential technical applications.

\section{Mechanical properties of vulcanizates at static and dynamic conditions}

Having established that $\mathrm{Me}(\mathrm{acac})$ with TEOA can effectively cure BIIR, we studied their effect on the mechanical behavior of the vulcanizates at static conditions as well as on the resistance to thermo-oxidative aging. The results are presented in Table 4. 


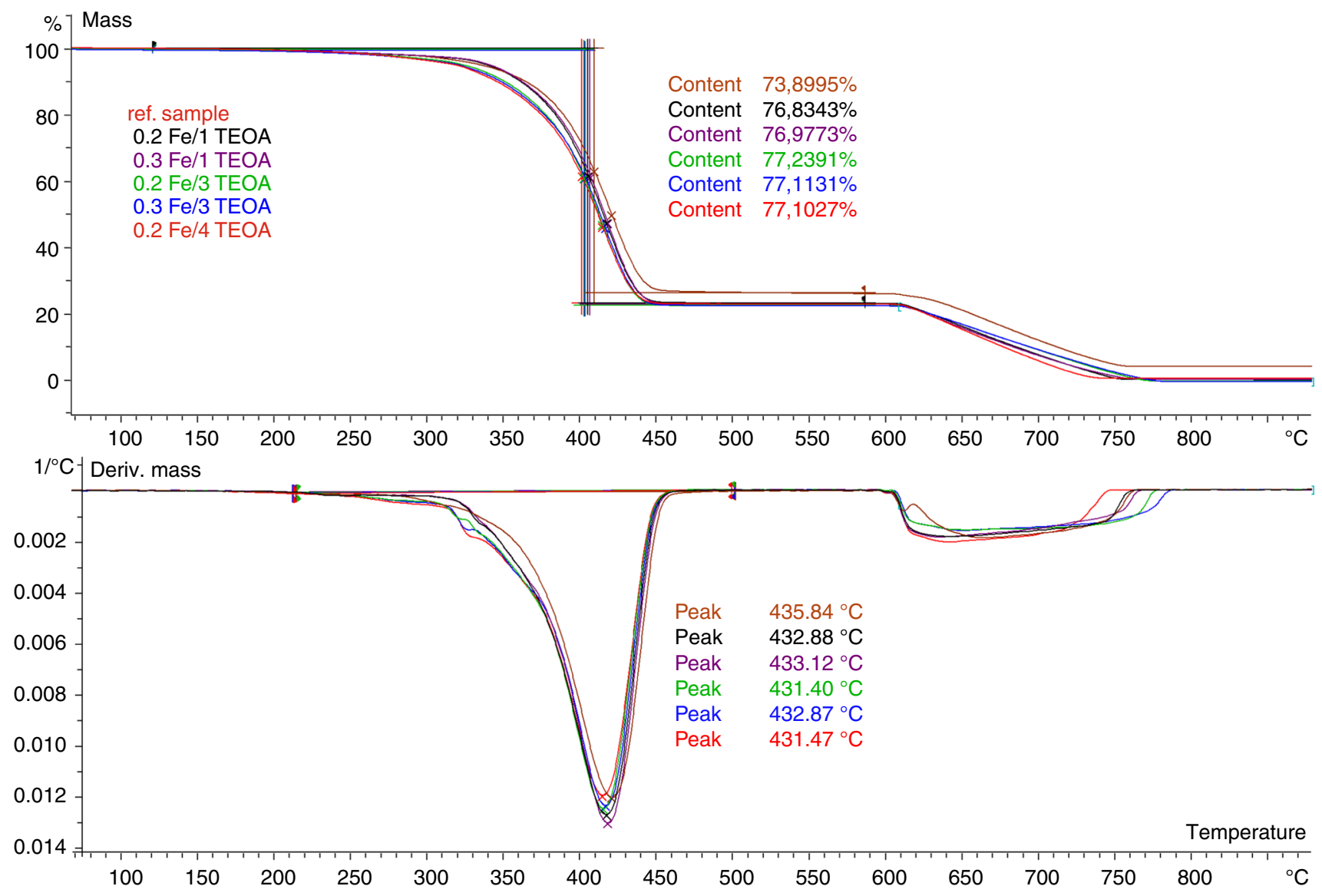

Fig. 2 TG/DTG curves of the BIIR vulcanizates with the Fe(acac)/TEOA curing system

Regarding the results presented in Table 4, the BIIR composites cured with $\mathrm{Me}(\mathrm{acac})$ exhibited an acceptable TS within the range of 9-14 MPa. The TS of the ref. sample cured with sulfur was $18 \mathrm{MPa}$. The vulcanizates containing $\mathrm{Fe}$ (acac) with 1 phr TEOA showed the highest TS. Increasing the content of TEOA reduced the TS of the $\mathrm{Fe}$ (acac)-containing vulcanizates but had no considerable influence on the TS of the BIIR with the other acetylacetonates. The highest EB was demonstrated by the BIIR cured with $\mathrm{Cu}(\mathrm{acac})$, which corresponds to the lowest degree of cross-linking. Mechanical properties are strongly connected with the cross-linking degree of vulcanizates, and therefore with the content of TEOA, which strongly influences the activity of the proposed curing systems. As mentioned, the BIIR cured with $\mathrm{Cu}(\mathrm{acac})$ was characterized with the lowest TS and the highest EB values resulting from the lowest cross-linking degree of the vulcanizates as confirmed earlier. For this reason, those results were not taken into consideration. The EB of the vulcanizate cured with sulfur was $465 \%$. The EB of the vulcanizates containing the new curing systems ranged from 271 to $685 \%$ and was decreasing with increasing $\mathrm{Me}(\mathrm{acac})$ and TEOA contents (with the exception of $4 \mathrm{phr}$ of TEOA). The closest elasticity to that of the ref. sample could be observed for the vulcanizate with the $0.3 \mathrm{Fe} / 1 \mathrm{TEOA}$ curing system (EB $491 \%$ ).

It is commonly known that transition metals could deteriorate the aging resistance of rubber products. Therefore, we studied the effect of the used transition metal acetylacetonates on the BIIR resistance to thermo-oxidative aging. The last parameter presented in Table 4 is the aging coefficient $\left(A_{\mathrm{f}}\right)$. A value of aging coefficient close to 1 represents a sample with perfect aging resistance, indicating that the aging process had no effect on the TS and the EB. It should be noticed that using $\mathrm{Me}$ (acac) did not affect the resistance of BIIR to thermo-oxidative aging. The examined vulcanizates are resistant to thermo-oxidative aging, which is confirmed by the $A_{\mathrm{f}}$ values in the range of $0.8-1.2$. The type and the 
Table 4 Mechanical properties and thermo-oxidative aging coefficient of BIIR vulcanizates

\begin{tabular}{lrll}
\hline Compound & TS/MPa & EB/\% & $A_{\mathrm{f}} /-$ \\
\hline Ref. sample & 18 & 465 & 0.9 \\
$0.2 \mathrm{Fe} / 1$ TEOA & 14 & 566 & 0.8 \\
$0.2 \mathrm{Mn} / 1$ TEOA & 10 & 618 & 1.0 \\
$0.2 \mathrm{Ni} / 1$ TEOA & 9 & 685 & 1.1 \\
$0.2 \mathrm{Cu} / 1$ TEOA & 4 & 860 & 1.2 \\
$0.3 \mathrm{Fe} / 1$ TEOA & 14 & 491 & 0.9 \\
$0.3 \mathrm{Mn} / 1$ TEOA & 10 & 358 & 1.1 \\
$0.3 \mathrm{Ni} / 1$ TEOA & 9 & 366 & 1.2 \\
$0.3 \mathrm{Cu} / 1$ TEOA & 3 & 572 & 0.7 \\
$0.2 \mathrm{Fe} / 3$ TEOA & 9 & 331 & 0.8 \\
$0.2 \mathrm{Mn} / 3$ TEOA & 11 & 332 & 1.0 \\
$0.2 \mathrm{Ni} / 3$ TEOA & 11 & 300 & 1.0 \\
$0.2 \mathrm{Cu} / 3$ TEOA & 4 & 466 & 0.9 \\
$0.3 \mathrm{Fe} / 3$ TEOA & 10 & 279 & 1.2 \\
$0.3 \mathrm{Mn} / 3$ TEOA & 11 & 271 & 1.1 \\
$0.3 \mathrm{Ni} / 3$ TEOA & 11 & 285 & 1.0 \\
$0.3 \mathrm{Cu} / 3$ TEOA & 3 & 483 & 1.1 \\
$0.2 \mathrm{Fe} / 4$ TEOA & 9 & 314 & 1.2 \\
$0.2 \mathrm{Mn} / 4$ TEOA & 11 & 351 & 1.0 \\
$0.2 \mathrm{Ni} / 4$ TEOA & 12 & 324 & 1.1 \\
$0.2 \mathrm{Cu} / 4$ TEOA & 4 & 461 & 1.1 \\
\hline
\end{tabular}

TS—-tensile strength, EB—elongation at break, $A_{\mathrm{f}}$-aging coefficient

content of $\mathrm{Me}$ (acac) as well as the content of TEOA had no significant influence on the aging resistance.

Rubber products often work under oscillating deformations. Therefore, in addition to the mechanical properties under static conditions, the dynamic mechanical properties are also important for the technological application of such materials. The influences of the new curing agents of the BIIR on the storage modulus $\left(E^{\prime}\right)$ and the mechanical loss factor $(\tan \delta$ ) were studied with DMA (Table 5). This method is very useful to study mechanical behavior of elastomers under dynamic conditions [26]. The measurements were performed only for the vulcanizates with the best tensile properties.

The storage modulus $E^{\prime}$ represents the ability of a viscoelastic material to store the deformation energy in an elastic manner. At low temperatures, below the $T_{\mathrm{g}}$, vulcanizates are rigid. $E^{\prime}$ is then the largest. The storage modulus of the BIIR vulcanizates decreased with increasing temperature (Fig. 3). In the temperature range of -90 to $0{ }^{\circ} \mathrm{C}$, the main loss of $E^{\prime}$ was observed due to the glass transition of the elastomer. Then, in the rubbery elastic region, the $E^{\prime}$ of the vulcanizates did not change considerably with the temperature. Comparing the influence of the sulfur curing system and the proposed curing agents on $E^{\prime}$ in the glassy state and the rubbery elastic region, it was observed that the vulcanizates cured with $\mathrm{Me}$ (acac), especially $\mathrm{Ni}$ (acac), showed a lower $E^{\prime}$, so a reduced ability to store energy during deformation. In the rubbery elastic region, the differences between $E^{\prime}$ of the ref. sample cured with sulfur and the vulcanizates containing $\mathrm{Me}$ (acac) were smaller than in the glassy state (approximately $1-2.5 \mathrm{MPa}$ in the temperature range of $25-60{ }^{\circ} \mathrm{C}$ ).

Taking into account the $\tan \delta$ as a function of temperature, $T_{\mathrm{g}}$ corresponds to the temperature of the $\tan \delta$ peak (Fig. 4). The shift of $T_{\mathrm{g}}$ to $2-4{ }^{\circ} \mathrm{C}$ lower temperatures, compared to the ref. sample cured with sulfur, was observed for all the vulcanizates containing metal complexes. It was due to the slightly lower cross-linking degree of these vulcanizates. Moreover, the vulcanizates cross-linked with $\mathrm{Me}(\mathrm{acac})$ were characterized with higher $\tan \delta$ at $T_{\mathrm{g}}$ and room temperature, which indicates better damping properties. Only at $60{ }^{\circ} \mathrm{C}$, the vulcanizates containing $\mathrm{Fe}$ (acac) and $\mathrm{Ni}(\mathrm{acac})$ were characterized with a slightly lower loss factor. Regarding the loss factor in the rubbery elastic region, the vulcanizate cured with $\mathrm{Mn}$ (acac) showed stable dynamic properties, since $\tan \delta$ was almost constant in the temperature range of $25-60{ }^{\circ} \mathrm{C}$. On the other hand, the $\tan \delta$ of the vulcanizates with $\mathrm{Fe}(\mathrm{acac})$ or $\mathrm{Ni}(\mathrm{acac})$ decreased with increasing temperature from 25 to $60{ }^{\circ} \mathrm{C}$.
Table 5 Dynamic mechanical properties of BIIR vulcanizates

\begin{tabular}{llllllll}
\hline Compound & $T_{\mathrm{g}} /{ }^{\circ} \mathrm{C}$ & $E_{(-100)}^{\prime} / \mathrm{MPa}$ & $E_{(25)}^{\prime} / \mathrm{MPa}$ & $E_{(60)}^{\prime} / \mathrm{MPa}$ & $\tan \delta_{(\mathrm{Tg})} /-$ & $\tan \delta_{(25)} /-$ & $\tan \delta_{(60)} /-$ \\
\hline ref. sample & -43 & 6857 & 3.7 & 3.2 & 1.17 & 0.16 & 0.16 \\
$0.3 \mathrm{Fe} / 1 \mathrm{TEOA}$ & -47 & 6495 & 2.8 & 2.2 & 1.31 & 0.18 & 0.13 \\
$0.3 \mathrm{Mn} / 3$ TEOA & -45 & 6059 & 2.7 & 2.1 & 1.25 & 0.19 & 0.18 \\
$0.2 \mathrm{Ni} / 4 \mathrm{TEOA}$ & -46 & 3917 & 1.2 & 1.4 & 1.19 & 0.21 & 0.13 \\
\hline
\end{tabular}

$T_{\mathrm{g}}$ - glass-transition temperature, $\tan \delta_{(\mathrm{Tg})}, \tan \delta_{(25)}, \tan \delta_{(60)}$-loss factor at $T_{\mathrm{g}}, 25^{\circ} \mathrm{C}$ and $60{ }^{\circ} \mathrm{C}$, respectively, $E_{(-100)}^{\prime}, E_{(25)}^{\prime}, E_{(60)}^{\prime}$-storage modulus at $-100{ }^{\circ} \mathrm{C}, 25^{\circ} \mathrm{C}$ and $60^{\circ} \mathrm{C}$, respectively 


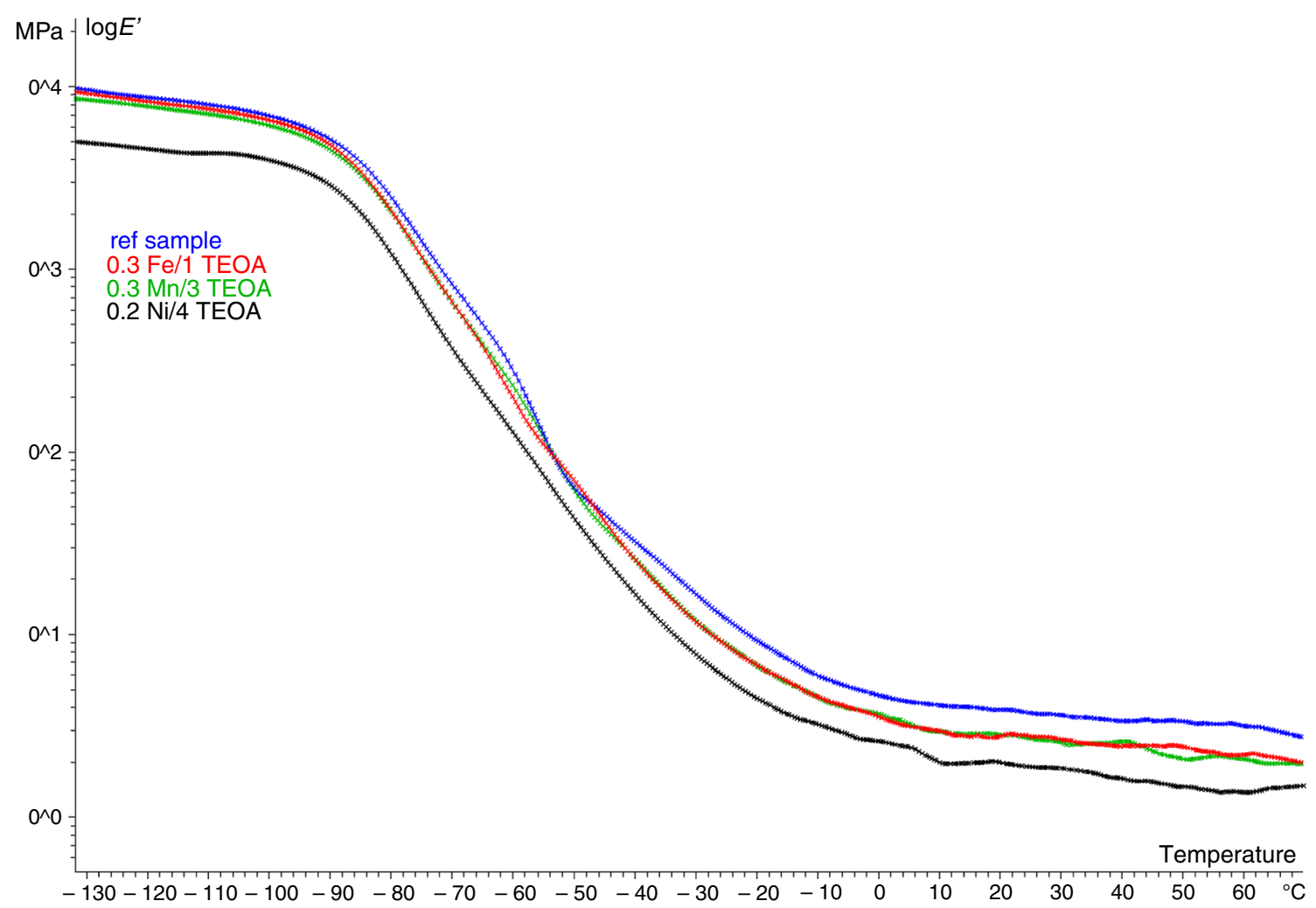

Fig. 3 Log of the storage modulus as a function of temperature for the BIIR vulcanizates

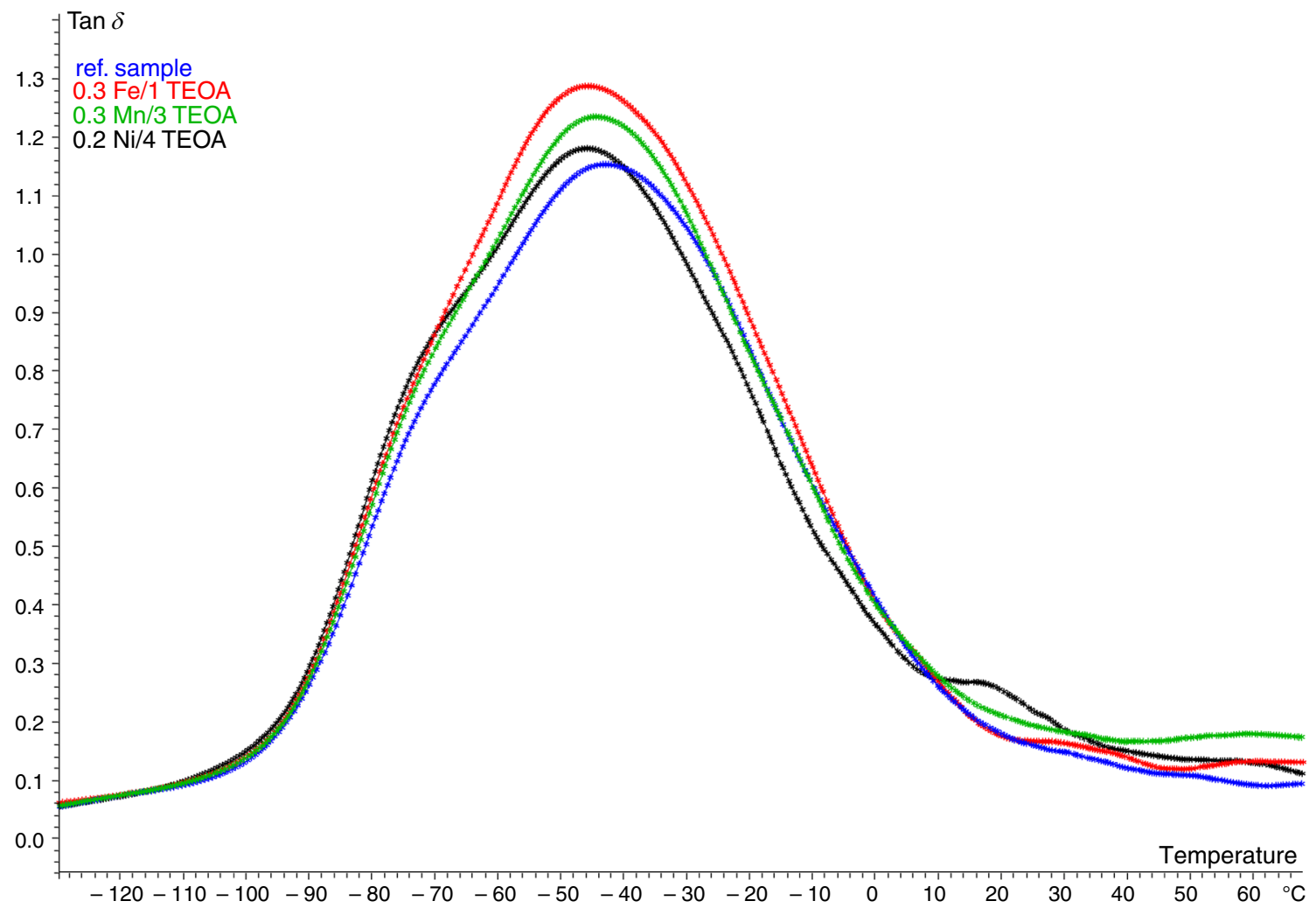

Fig. 4 Mechanical loss factor as a function of temperature for the BIIR vulcanizates 


\section{Conclusions}

Selected Me(acac), such as Fe(acac), Mn(acac) and Ni(acac), are effective curing agents of BIIR, which was confirmed by the measurement results of the $\Delta M$ during vulcanization and the degree of vulcanizate cross-linking. Both the metal complex and TEOA have great influences on the activity of the proposed new curing system.

The most active curing agent, from the newly proposed ones, seems to be $\mathrm{Fe}$ (acac), which allows for the highest $\Delta M$ during vulcanization and the highest $\alpha_{\mathrm{T}}$ of the vulcanizates. Moreover, the application of $\mathrm{Fe}(\mathrm{acac})$ in the presence of 3-4 phr of TEOA results in a shorter TC95 and lower onset vulcanization temperature compared to the BIIR cured with a sulfur curing system used in the rubber industry. Both the shorter vulcanization time and the lower vulcanization temperature could be very beneficial from the economical point of view.

The BIIR vulcanizates cured with $\mathrm{Me}$ (acac) exhibit TS in the range of 9-14 MPa. In addition, the vulcanizates containing 3 or 4 phr TEOA show a higher $\alpha_{\mathrm{T}}$ than the ref. sample cross-linked with sulfur. Using the Me(acac)/TEOA, curing system does not deteriorate the resistance of BIIR to thermo-oxidative aging, which is confirmed by the $A_{\mathrm{f}}$ values in the range of $0.8-1.2$.

The vulcanizates containing 3 or 4 phr TEOA exhibit a lower thermal stability than the sulfur-cured BIIR or the vulcanizates with $1 \mathrm{phr}$ TEOA. The reduction in decomposition temperature for the vulcanizates with 3 or 4 phr TEOA results from the low thermal stability of this ingredient, which starts decomposing at the temperature above $150{ }^{\circ} \mathrm{C}$. However, such a reduction in vulcanizate thermal stability should not considerably affect their potential technical applications. The BIIR cross-linked with Me(acac) exhibits higher $\tan \delta$ at $T_{\mathrm{g}}$ and room temperature, which indicates better damping properties than the sulfur-cured rubber.

The presented results confirmed that the Heck-type reactions can be successfully used in the vulcanization of halogenated rubbers. This can be a considerable breakthrough in the rubber technology. The proposed curing system, consisting of $\mathrm{Me}$ (acac) and TEOA, is also a promising tool for cocuring between halogenated rubber and conventional diene rubber, which is especially important in the tire industry. The greatest advantage of using proposed $\mathrm{Me}$ (acac) as curing agents is that a high activity can be achieved with a very small amount of $\mathrm{Me}(\mathrm{acac})$. Another advantage is the simple recipe. The components of the proposed curing systems are active enough, and there is no need to use the toxic activators and accelerators of vulcanization as in the case of a sulfur curing system. This makes Me(acac) valuable not only from an economic point of view but also taking into account human health and the environment.
Funding This work was supported by Young Scientists' Fund at the Faculty of Chemistry, Lodz University of Technology [Grant W-3D/ FMN/34G/2016].

\section{Compliance with ethical standards}

Conflict of interest The authors declare that they have no conflict of interest.

Informed consent Informed consent was obtained from all individual participants included in the study.

Open Access This article is distributed under the terms of the Creative Commons Attribution 4.0 International License (http://creativeco mmons.org/licenses/by/4.0/), which permits unrestricted use, distribution, and reproduction in any medium, provided you give appropriate credit to the original author(s) and the source, provide a link to the Creative Commons license, and indicate if changes were made.

\section{References}

1. Rybiński P, Kucharska-Jastrzabek A, Janowska G. Thermal properties of diene elastomers. Polym Sci B. 2014;56:477-86.

2. Crompton TR. Polymer reference book. 1st ed. Shawbury: Rapra Technology Limited; 2006. p. 305-73.

3. Ginic-Markovic M, Choudhury NR, Dimopoulos M, Willims DRG, Matisons J. Characterization of elastomer compounds by thermal analysis. Thermochim Acta. 1998;316:87-95.

4. Hamed GR. Materials and compounds. In: Gent AN, editor. Engineering with rubber. How to design rubber components. 3rd ed. Munich: Hanser Publishers; 2012. p. 11-7.

5. Darren JT. The cure chemistry of brominated butyl rubber: a model compound approach. Ph.D. thesis. Queen's University, Kingston, Ontario, Canada; 1999.

6. Waddell WH, Tsou AH. Butyl Rubbers. In: Rodgers B, editor. Rubber compounding, chemistry and applications. 2nd ed. Boca Raton: CRC Press; 2015. p. 109-34.

7. Smolentseva II, Mashukov VI, Korotkova EI. Determination of unsaturation level, halogen content, and main forms of isoprene units in halogenated butyl rubbers by ${ }^{1} \mathrm{H}$ NMR spectroscopy. J Appl Spectrosc. 2015;82:465-9.

8. Scagliusi SR, Cardoso ELC, Lugao AB. Effect of gamma radiation on chlorobutyl rubber vulcanizaed by three different crosslinking systems. Radiat Phys Chem. 2012;81:1370-3.

9. Kruzelak J, Sykora R, Hudec I. Sufphur and peroxide vulcanisation of rubber compounds-overview. Chem Pap. 2016;70:1533-55.

10. Akiba M, Hashim AS. Vulcanization and crosslinking in elastomers. Prog Polym Sci. 1997;22:475-521.

11. Rajan VV, Dierkes WK, Joseph R, Noordermeer JWM. Science and technology of rubber reclamation with special attention to NR-based waste latex products. Prog Polym Sci. 2006;31:811-34.

12. Shanmugam KVS. Peroxide curable butyl rubber derivatives. Ph.D. thesis. Queen's University, Kingston, Ontario, Canada; 2012.

13. Ohm RF. Vulcanization agents for specialty elastomers. In: Klingender RC, editor. Handbook of specialty elastomers. 1st ed. Boca Raton: CRC Press; 2008. p. 409-28. 
14. Waghmode SB, Arbuj SS, Wani BN, Gopinath CS. Palladium chloride catalyzed photochemical Heck reaction. Can J Chem. 2013;91:348-51.

15. Gholivand K, Salami R, Farshadfar K, Butcher RJ. Synthesis and structural characterization of $\mathrm{Pd}(\mathrm{II})$ and $\mathrm{Cu}$ (II) complexes containing dithiophosphorus ligand and their catalytic activities for Heck reaction. Polyhedron. 2016;119:267-76.

16. Jutand A. Mechanisms of the Mizoroki-Heck reaction. In: Oestreich M, editor. The Mizoroki-Heck rection. 1st ed. Chichester: Wiley; 2009. p. 1-50.

17. Jagtap S. Heck reaction-state of the art. Catalysts. 2017;7:267-320.

18. Wang S, Yang G. Recent developments in low-cost TM-catalyzed Heck-type reactions ( $\mathrm{TM}=$ transition metal, $\mathrm{Ni} \mathrm{Co}, \mathrm{Cu}, \mathrm{Fe}$ ). Catal Sci Technol. 2016;6:2862-76.

19. Dziemidkiewicz A, Pingot M, Maciejewska M. Metal complexes as new pro-ecological crosslinking agents for chloroprene rubber based on Heck coupling reaction. Rubber Chem Technol. 2019. https://doi.org/10.5254/rct.19.81465.

20. Sae-oui P, Sirisinha C, Thepsuwan U, Hatthapanit K. Dependence of mechanical and aging properties of chloroprene rubber on silica and ethylene thiourea loadings. Eur Polym J. 2007;43:185-93.

21. Sowinska A, Maciejewska M. Thermal analysis applied to study the influence of ionic liquids on the vulcanization, thermal stability and damping properties of ethylene-propylene-diene rubber. J Therm Anal Calorim. 2019. https://doi.org/10.1007/s1097 3-019-08198-5.

22. Costa HM, Ramos VD, Campbell BC, Andrade MC. Thermal analysis of the sulfur vulcanization. J Therm Anal Calorim. 2017;129:755-66.

23. Vasilakos SP, Tarantili PA. In situ monitoring by DSC and modeling curing of vinyl polysiloxanes in layered silicate nanocomposites. J Therm Anal Calorim. 2017;127:2049-58.

24. Maciejewska M, Sowinska A. Thermal characterization of the effect of fillers and ionic liquids on the vulcanization and properties of acrylonitrile-butadiene elastomer. J Therm Anal Calorim. 2019. https://doi.org/10.1007/s10973-019-08187-8.

25. Yilmaz VT, Topcu Y, Karadag A. Thermal decomposition of triethanolamine and monoethanolethylenediamine complexes of some transition metal saccharinates. Thermochim Acta. 2002;383:129-35.

26. Gaca M, Zaborski M. The properties of ethylene-propylene elastomers obtained with the use of a new cross-linking substance. J Therm Anal Calorim. 2016. https://doi.org/10.1007/s1097 3-016-5404-z.

Publisher's Note Springer Nature remains neutral with regard to jurisdictional claims in published maps and institutional affiliations. 